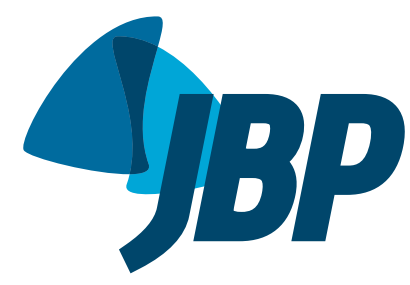

1. Irmandade da Santa Casa de Misericórdia de Porto Alegre Porto Alegre (RS) Brasil.

2. Universidade Federal do Rio de Janeiro, Rio de Janeiro (RJ) Brasil.

a. (iD) http://orcid.org/0000-0003-0166-5082

b. (iD) http://orcid.org/0000-0002-3758-5001

c. (iD http://orcid.org/0000-0001-8797-7380

d. (iD) http://orcid.org/0000-0002-8432-2247

e. (iD http://orcid.org/0000-0003-1984-4636

Submitted: 11 January 2018 Accepted: 2 March 2018

Study carried out at the Irmandade da Santa Casa de Misericórdia de Porto Alegre, Porto Alegre (RS) Brasil.

\section{Chest X-ray and chest CT findings in patients diagnosed with pulmonary tuberculosis following solid organ transplantation: a systematic review}

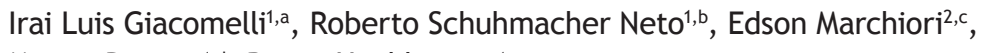
Marisa Pereira, ${ }^{1, \mathrm{~d}}$, Bruno Hochhegger ${ }^{1, \mathrm{e}}$

\begin{abstract}
The objective of this systematic review was to select articles including chest X-ray or chest CT findings in patients who developed pulmonary tuberculosis following solid organ transplantation (lung, kidney, or liver). The following search terms were used: "tuberculosis"; "transplants"; "transplantation"; "mycobacterium"; and "lung". The databases used in this review were PubMed and the Brazilian Biblioteca Virtual em Saúde (Virtual Health Library). We selected articles in English, Portuguese, or Spanish, regardless of the year of publication, that met the selection criteria in their title, abstract, or body of text. Articles with no data on chest CT or chest X-ray findings were excluded, as were those not related to solid organ transplantation or pulmonary tuberculosis. We selected 29 articles involving a collective total of 219 patients. The largest samples were in studies conducted in Brazil and South Korea (78 and 35 patients, respectively). The imaging findings were subdivided into five common patterns. The imaging findings varied depending on the transplanted organ in these patients. In liver and lung transplant recipients, the most common pattern was the classic one for pulmonary tuberculosis (cavitation and "tree-in-bud" nodules), which is similar to the findings for pulmonary tuberculosis in the general population. The proportion of cases showing a miliary pattern and lymph node enlargement, which is most similar to the pattern seen in patients coinfected with tuberculosis and HIV, was highest among the kidney transplant recipients. Further studies evaluating clinical data, such as immunosuppression regimens, are needed in order to improve understanding of the distribution of these imaging patterns in this population.
\end{abstract}

Keywords: Tomography, X-ray computed; Radiography; Tuberculosis, pulmonary; Lung/ transplantation; Kidney/transplantation; Liver/transplantation.

\section{INTRODUCTION}

Pulmonary tuberculosis is an infection that is spread by airborne transmission and has a major impact on morbidity and mortality in several countries. In the year 2014, the global incidence of tuberculosis was approximately 133 cases/100,000 population, underdeveloped countries accounting for the majority of those cases, being 281 cases/100,000 population in Africa and approximately 33 cases/100,000 population in Brazil. ${ }^{(1,2)}$

Pulmonary tuberculosis occurs in two principal forms: primary, responsible for only $5 \%$ of cases, in which the inhaled tuberculosis bacillus infects the airway and is not immediately contained by the host immunity; and post-primary, responsible for $95 \%$ of cases, in which the principal focus of pulmonary infection is contained by the host immunity, with subsequent reactivation of the disease.

The incidence of pulmonary tuberculosis can be up to 20 times higher among recipients of solid organ transplants than among immunocompetent individuals in areas where tuberculosis is not endemic. ${ }^{(3,4)}$

The clinical manifestations of pulmonary tuberculosis in immunosuppressed patients, including solid organ transplant recipients, can often be attenuated, the typical signs and symptoms, including fever, productive cough, and night sweats, often being absent, which hinders and delays the correct diagnosis.

For immunosuppressed patients with acute or subacute respiratory symptoms, CT is the imaging modality of choice, often strongly suggesting the diagnostic hypothesis of pulmonary tuberculosis. Many radiological findings have been described in this disease, including the miliary pattern, consolidations, ground-glass attenuation opacities, cavitation with centrilobular "tree-in-bud" nodules, diffuse pulmonary infiltrates, mediastinal or hilar lymph node enlargement, and pleural effusion. ${ }^{(4-6)}$

There have been few studies reporting the tomographic findings of pulmonary tuberculosis in patients undergoing

Correspondence to:

Irai Luis Giacomelli. Irmandade da Santa Casa de Misericórdia de Porto Alegre, Rua Professor Annes Dias, 295, Centro Histórico, CEP 90020-090, Porto Alegre,

RS, Brasil.

Tel.: 5551 8190-9256. E-mail: iraigiacomelli@gmail.com

Financial support: None. 
solid organ transplantation. The objective of the present study was to conduct a systematic review of the literature in order to identify the main radiological patterns of tuberculosis in this population.

\section{METHODS}

\section{Search strategies}

For this systematic review, we followed the precepts of the Cochrane Handbook for Systematic Reviews of Interventions, ${ }^{(7)}$ which involve formulating the research question; locating and selecting scientific articles; and critically evaluating the articles selected. The research question used was as follows: What are the presentations of pulmonary tuberculosis on chest X-ray and chest CT in solid organ transplant recipients? The research was carried out by five researchers, four of whom carried out the searches for articles in an independent and blinded fashion, whereas the fifth was the reviewer, being consulted in cases of uncertainty in order to reach a consensus. The following search terms were used: "tuberculosis"; "transplants"; "transplantation"; "mycobacterium"; and "lung". Those search terms were selected from the list of descriptors available from the U.S. National Library of Medicine Medical Subject Headings and the Brazilian Descritores em Ciências da Saúde da Biblioteca Virtual em Saúde (Virtual Health Library Descriptors in the Health Sciences). For the research, the following online databases were used: PubMed, which includes Medline and the Cochrane Library; and the Virtual Health Library, which includes LILACS, the Spanish Bibliographic Index of the Health Sciences, and SciELO. The searches were conducted between January and October of 2016.

\section{Selection criteria}

We selected articles in English, Portuguese, or Spanish, published between January of 1980 and October of
2017, involving human subjects, in which the title, abstract, or body of the text had some relationship with the study objective. Duplicate articles were excluded, as were those for which abstracts were not available, those that did not contain information on chest X-ray or chest CT findings, and those that were not related to solid organ transplantation or pulmonary tuberculosis. No search filters were applied. The article selection process is depicted as a flow chart in Figure 1, according to the recommendations of the preferred reporting items for systematic reviews and meta-analyses. ${ }^{(8)}$

\section{Data analysis}

On the basis of the reading of the abstracts of the studies identified, the full texts of the selected articles were retrieved. After the full texts of the articles had been read, the following data were extracted: author names, year of publication, the country where the research was conducted, sample size, patient age, patient genders, time from transplantation to diagnosis of tuberculosis, transplanted organ, chest CT findings, and chest $\mathrm{X}$-ray findings. The selected articles were divided, by their study design, into case series and case reports.

The results obtained from the evaluation of the selected articles served as the basis for the evaluation of the demographic data related to the patients in the sample and chest imaging data. The chest imaging data were divided into five presentation groups, according to the predominant finding: miliary nodules; cavitation and centrilobular "tree-in-bud" nodular pattern; consolidation and ground-glass attenuation; mediastinal lymph node enlargement; and pleural effusion. This classification followed the criteria established by the Fleischner Society. ${ }^{(9)}$

For articles that discriminated the presentation of tuberculosis as pulmonary only, without additional details, the chest imaging data were classified as the

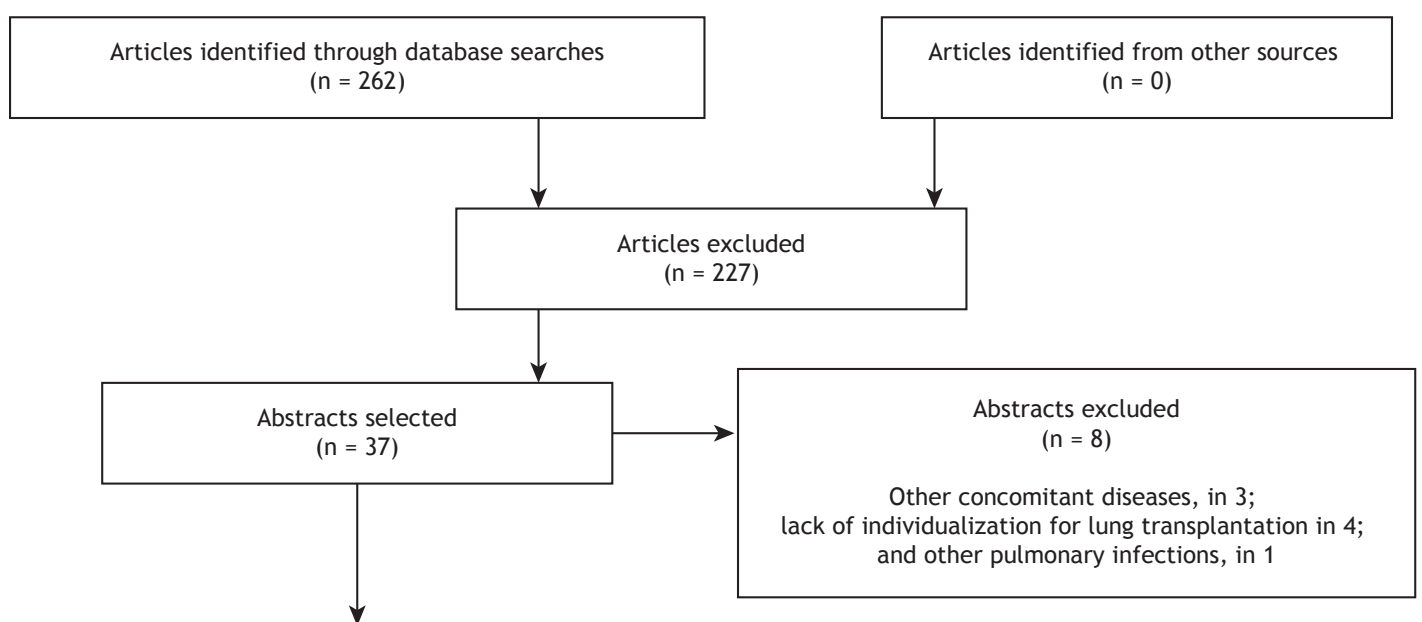

Full texts selected for inclusion in the study

$(n=29)$

Figure 1. Selection of the articles analyzed in the present review. 
typical presentation of tuberculosis and were inserted into the cavitation and centrilobular in "tree-in-bud" nodular pattern group, as were those for articles that described small pleural effusion, because the classification was based on the predominant pattern. Three abstracts were excluded because the pulmonary tuberculosis patients evaluated also had pulmonary Kaposi's sarcoma or pulmonary infection. ${ }^{(10-12)}$ Four cases series were excluded for generalizing imaging findings to recipients of more than one solid organ transplant, ${ }^{(13-16)}$ as was one case series for generalizing imaging findings to patients with tuberculosis or other respiratory infections. ${ }^{(17)}$ The demographic data presented in two articles were censored, because they combined groups of interest (thoracic pathologies) with other groups (nonthoracic pathologies). ${ }^{(5,18)}$

\section{RESULTS}

From among the articles involving solid organ transplant recipients with pulmonary tuberculosis, we selected 16 case series ${ }^{(5,18-32)}$ and 13 case reports ${ }^{(33-45)}$ in which chest imaging findings were available, with a collective total of 219 patients. The data had been obtained in countries on all continents. Among the selected studies, the largest patient samples (78 and 35 patients, respectively) were in a study conducted in Brazil and a study conducted in South Korea, as can be seen in Table 1. $(26,29,31,32)$

Pulmonary tuberculosis occurs most commonly in men, who accounted for $65 \%$ and $72 \%$ of the sample, respectively, in the two most representative studies. ${ }^{26,29)}$ The majority of patients with pulmonary tuberculosis were between the fourth and sixth decades of life. The diagnosis of pulmonary tuberculosis was made 3-12 months after transplantation (Table 1).
The incidence of tuberculosis cases in relation to the number of transplants of a given organ at each institution ranged from $0.09 \%$ to $4.7 \%$ of the cases, with a mean incidence of $1.12 \%$. We identified 53 cases of pulmonary tuberculosis among lung transplant recipients, with a predominance of the cavitation/ tree-in-bud pattern in 35 (66\%) of the cases (Table 2 ).

The largest patient sample was composed of kidney transplant recipients ( 96 patients); the most common pattern was cavitation and centrilobular nodules in a tree-in-bud pattern, which was seen in approximately one third of those patients, followed by the "lymph node enlargement" and "pleural effusion" categories, which together also accounted for a third of the cases (Table 3). We identified 51 liver transplant recipients, $62 \%$ of whom had cavitation and centrilobular nodules in a bud-tree pattern (Table 4).

\section{DISCUSSION}

To our knowledge, this is the first systematic review of chest imaging findings in solid organ transplant recipients diagnosed with pulmonary tuberculosis. $A$ collective total of 219 cases were analyzed. Among the 219 cases analyzed, 96, 70, and 53 were in kidney, liver, and lung transplant recipients, respectively. This proportional distribution of cases of pulmonary tuberculosis probably reflects the similar proportional distribution of transplantations by organ.

In the articles selected (i.e., those that contained imaging findings), the prevalence of tuberculosis among transplant recipients ranged from $0.09 \%$ to $4.7 \%$, thus not representing the total number of cases, which was not the purpose of the present study. These proportions allow us to infer only an approximate value for the true prevalence.

Table 1. Data obtained from the case series selected in the present systematic review.

\begin{tabular}{|c|c|c|c|c|}
\hline Reference & Country & $\begin{array}{l}\text { Organ } \\
\text { transplanted }\end{array}$ & Cases, n & $\begin{array}{l}\text { Time from transplantation to } \\
\text { diagnosis of tuberculosis, months }\end{array}$ \\
\hline \multirow{3}{*}{ Torre-Cisneros et al. ${ }^{(5)}$} & \multirow{3}{*}{ Spain } & Lung & 4 & NA \\
\hline & & Kidney & 6 & NA \\
\hline & & Liver & 7 & NA \\
\hline Aslani et al. ${ }^{(18)}$ & Iran & Kidney & 16 & NA \\
\hline Kaaroud et al. ${ }^{(19)}$ & Tunisia & Kidney & 6 & NA \\
\hline Mortensen et al. ${ }^{(20)}$ & USA & Lung & 3 & 3.7 \\
\hline Kesten et al. ${ }^{(21)}$ & USA & Lung & 2 & 3 \\
\hline Schulma et al.(22) & USA & Lung & 2 & 3 \\
\hline Ram et al. (23) & India & Kidney & 16 & NA \\
\hline Shreeniwas et al. (24) & USA & Lung & 1 & 3 \\
\hline Schulma et al. (25) & USA & Lung & 2 & 11 \\
\hline Pereira et al. ${ }^{(26)}$ & Brazil & Kidney & 40 & 8.6 \\
\hline Malouf et al.(27) & Australia & Lung & 12 & NA \\
\hline Jiang et al. ${ }^{(28)}$ & China & Kidney & 7 & 12 \\
\hline Lyu et al. ${ }^{(29)}$ & South Korea & Liver & 35 & 10 \\
\hline Meyers et al. ${ }^{(30)}$ & USA & Liver & 9 & NA \\
\hline Giacomelli et al. ${ }^{(31)}$ & Brazil & Lung & 19 & 3.2 \\
\hline Schuhmacher Neto et al. ${ }^{(32)}$ & Brazil & Liver & 19 & 2.6 \\
\hline
\end{tabular}

NA: not available. 
Table 2. Chest X-ray and chest CT findings in lung transplant recipients.

\begin{tabular}{lcccc}
\multicolumn{1}{c}{ Finding } & X-ray & CT & n & $\%$ \\
\hline $\begin{array}{lcccc}\text { Ground-glass opacity/ } \\
\text { consolidations }\end{array}$ & 1 & 9 & 10 & 18.9 \\
$\begin{array}{l}\text { Cavitation/tree-in-bud pattern } \\
\text { Mediastinal lymph node }\end{array}$ & 24 & 11 & 35 & 66.0 \\
enlargement & 0 & 4 & 4 & 7.5 \\
Miliary pattern & 0 & 2 & 2 & 3.8 \\
Pleural effusion & 2 & 0 & 2 & 3.8 \\
Total & 27 & 26 & 53 & 100 \\
\hline
\end{tabular}

Table 3. Chest X-ray and chest CT findings in kidney transplant recipients.

\begin{tabular}{lcccc}
\multicolumn{1}{c}{ Finding } & X-ray & CT & n & $\%$ \\
$\begin{array}{lcccc}\text { Ground-glass opacity/ } \\
\text { Consolidations }\end{array}$ & 0 & 9 & 9 & 9.38 \\
$\begin{array}{l}\text { Cavitation/tree-in-bud pattern } \\
\text { Mediastinal lymph node }\end{array}$ & 5 & 29 & 34 & 35.4 \\
enlargement & 6 & 8 & 14 & 14.6 \\
Miliary pattern & 1 & 22 & 23 & 24 \\
Pleural effusion & 11 & 5 & 16 & 16.7 \\
Total & 23 & 73 & 96 & 100 \\
\hline
\end{tabular}

Table 4. Chest X-ray and chest $\mathrm{CT}$ findings in liver transplant recipients.

\begin{tabular}{lcccc}
\multicolumn{1}{c}{ Finding } & X-ray & CT & n & $\%$ \\
Ground-glass opacity/ & 0 & 1 & 1 & 1.4 \\
consolidations & 0 & 47 & 47 & 67.2 \\
Cavitation/tree-in-bud pattern & 0 & 10 & 10 & 14.3 \\
$\begin{array}{l}\text { Mediastinal lymph node } \\
\text { enlargement }\end{array}$ & 0 & 12 & 12 & 17.1 \\
Miliary pattern & 0 & 70 & 70 & 100 \\
Total & 0 & & & \\
\hline
\end{tabular}

The studies with the highest numbers of patients included were conducted in Brazil, South Korea, India, and Iran. It is necessary to emphasize that tuberculosis is endemic only in certain countries, unlike most other opportunistic diseases, which are ubiquitous. The incidence of pulmonary tuberculosis among transplant recipients will always be related to the incidence of tuberculosis in the region in which the patient and donor reside.

Among the patient samples evaluated, there was a predominance of men, with an approximate male:female ratio of $2: 1$. However, it should be borne in mind that approximately half of the articles did not provide demographic data or extrapolated them to diseases other than tuberculosis and were therefore not included. The majority of the patients were between the fourth and sixth decades of life. A complete evaluation of demographic findings might be more appropriate if all articles on solid organ transplant recipients with tuberculosis were evaluated, rather than only those including chest imaging findings.

Data on the time from transplantation to the diagnosis of tuberculosis were present in approximately half of the studies of lung or kidney transplant recipients and most of those of liver transplant recipientsThe time from transplantation to the diagnosis of tuberculosis ranged from 3 to 11 months for lung transplant recipients, with medians between 3 and 4 months, compared with 8-12 months for kidney transplant recipients and 2.6-12 months for liver transplant recipients.

Approximately $66 \%$ of the lung transplant recipients with tuberculosis showed a typical pattern of pulmonary involvement (cavitations and the tree-in-bud pattern), atypical patterns occurring in approximately one third of cases. Unlike the lung transplant recipients, only 34 of the 96 kidney transplant recipients-approximately one third-showed the classic presentation of pulmonary tuberculosis, whereas approximately one quarter showed a miliary presentation and approximately one third showed a predominance of lymph node enlargement or pleural effusion.

Most (76\%) of the data obtained for kidney transplant recipients were from CT findings, as were all (100\%) of the data obtained for liver transplant recipients. In the latter case, the majority $(67.2 \%)$ had the typical presentation of pulmonary tuberculosis. None of the liver transplant recipients showed a predominance of pleural effusion.

In patients with tuberculosis/HIV coinfection, pulmonary tuberculosis was found to be most often accompanied by lymph node enlargement and miliary disease. ${ }^{(46)}$ Hilar and mediastinal lymph node enlargement occurred in $60 \%$ of such patients. ${ }^{(47,48)}$

On the basis of our results, we can infer that the presentation of pulmonary tuberculosis in kidney transplant recipients tend to be most similar to that of patients with tuberculosis/HIV coinfection (i.e., a greater proportion of cases of lymph node enlargement and miliary involvement); the same was not true for lung and liver transplant recipients, in whom the presentation tended to be more similar to that seen in the general population.

In the articles selected for this review, there were other presentations of pulmonary tuberculosis not defined in the classification described in the methods section. Boedefeld et al. ${ }^{(35)}$ reported a case of pulmonary tuberculosis accompanied by pericardial involvement. There were also two reported cases of transplant recipients presenting with pulmonary tuberculosis in the form of masses. ${ }^{(39,45)}$

There were reports of pulmonary tuberculosis in solid organ transplant recipients with normal chest X-rays findings, as well as in healthy patients, with incidence rates that vary widely across studies. Lyu et al. ${ }^{(29)}$ also identified patients with normal chest CT findings who developed pulmonary tuberculosis. Therefore, normal chest X-rays do not exclude a diagnosis of pulmonary tuberculosis in solid organ transplant recipients. The incidence of that combination might be better evaluated in clinical studies of tuberculosis in this population. In a case report, Carlsen et al. ${ }^{(42)}$ stated that the presence of calcified mediastinal lymph nodes can raise the suspicion of a diagnosis of tuberculosis. 
In summary, the majority of lung and liver transplant recipients with pulmonary tuberculosis show the classic cavitation and tree-in-bud nodular presentation (66.0 and $67.2 \%$, respectively). However, that presentation is seen in only one third of kidney transplant recipients with pulmonary tuberculosis, in whom the presentation is similar to that seen in patients coinfected with tuberculosis and HIV. Studies evaluating sociodemographic differences and, in particular, the immunosuppressive regimen could help identify new hypotheses for the predominance of the atypical presentation of pulmonary tuberculosis in kidney transplant recipients.

\section{REFERENCES}

1. World Health Organization [homepage on the Internet]. Geneva: World Health Organization; C2016 [cited 2016 Aug 7]. Media centre: Tuberculosis; [about 8 screens]. Available from: http://www.who.int/ mediacentre/factsheets/fs104/en/

2. Brasil. Ministério da Saúde. Secretaria de Vigilância em Saúde. [homepage on the Internet]. Brasília: Ministério da Saúde; [cited 2016 Jun 10]. Tuberculose - 2015: Detectar, tratar e curar: desafios e estratégias brasileiras frente à tuberculose. Boletim Epidemiológico. 2015;46(09). [Adobe Acrobat document, 19p.]. Available from: http:// portalarquivos2.saude.gov.br/images/pdf/2015/marco/27/2015-007BE-Tuberculose--para-substitui---o-no-site.pdf

3. Subramanian A, Dorman S; AST Infectious Diseases Community of Practice. Mycobacterium tuberculosis in solid organ transplant recipients. Am J Transplant. 2009;9 Suppl 4:S57-62. https://doi. org/10.1111/j.1600-6143.2009.02894.x

4. Singh N, Paterson DL. Mycobacterium tuberculosis infection in solidorgan transplant recipients: impact and implications for management. Clin Infect Dis. 1998;27(5):1266-77. https://doi.org/10.1086/514993

5. Torre-Cisneros J, Doblas A, Aguado JM, San Juan R, Blanes M, Montejo M, et al. Tuberculosis after solid-organ transplant: incidence, risk factors, and clinical characteristics in the RESITRA (Spanish Network of Infection in Transplantation) cohort. Clin Infect Dis. 2009;48(12):1657-65. https://doi.org/10.1086/599035

6. Kiyono K, Sone S, Sakai F, Imai Y, Watanabe T, Izuno I, et al. The number and size of normal mediastinal lymph nodes: a postmortem study. AJR Am J Roentgenol. 1988;150(4):771-6. https://doi. org/10.2214/ajr.150.4.771

7. Higgins JPT, Green S, editors. Cochrane Handbook for Systematic Reviews of Interventions Version 5.1.0 [updated March 2011]. The Cochrane Collaboration; 2011.

8. Moher D, Liberati A, Tetzlaff J, Altman DG; PRISMA Group. Preferred reporting items for systematic reviews and meta-analyses: the PRISMA statement. PLoS Med. 2009;6(7):e1000097. https://doi. org/10.1371/journal.pmed.1000097

9. Hansell DM, Bankier AA, MacMahon H, McLoud TC, Müller $\mathrm{NL}$, Remy J. Fleischner Society: glossary of terms for thoracic imaging. Radiology. 2008;246(3):697-722. https://doi.org/10.1148/ radiol. 2462070712

10. Kalra V, Agarwal SK, Khilnani GC, Kapil A, Dar L, Singh UB, et al. Spectrum of pulmonary infections in renal transplant recipients in the tropics: a single center study. Int Urol Nephrol. 2005;37(3):551-9. https://doi.org/10.1007/s11255-005-4012-9

11. Rathi M, Gundlapalli S, Ramachandran R, Mohindra S, Kaur H, Kumar $V$, et al. A rare case of Cytomegalovirus, Scedosporium apiospermum and Mycobacterium tuberculosis in a renal transplant recipient. BMC Infect Dis. 2014;14:259. https://doi.org/10.1186/1471-2334-14-259

12. Krayem AB, Abdullah LS, Raweuily EA, Wali SO, Rawas MM, Samman YS, et al. The diagnostic challenge of pulmonary Kaposi's sarcoma with pulmonary tuberculosis in a renal transplant recipient: a case report. Transplantation. 2001;71(10):1488-91. https://doi. org/10.1097/00007890-200105270-00024

13. Tabarsi P. Farshidpour M, Marjani M, Baghaei $P$, Yoisefzadeh $A$, Najafizadeh $\mathrm{K}$, et al. Mycobacterial infection and the impact of rifabutin treatment in organ transplant recipients: a single-center study. Saudi J Kidney Dis Transpl. 2015;26(1):6-11. https://doi. org/10.4103/1319-2442.148710

14. Schultz V, Marroni CA, Amorim CS, Baethgen LF, Pasqualotto AC Risk factors for hepatotoxicity in solid organ transplants recipients being treated for tuberculosis. Transplant Proc. 2014;46(10):3606-10. https://doi.org/10.1016/..transproceed.2014.09.148

15. Singh N, Patterson DL. Mycobacterium tuberculosis infection in solidorgan transplant recipients: impact and implications for management. Clin Infect Dis. 1998;27(5):1266-77. https://doi.org/10.1086/514993

16. Lopez de Castilla D, Schluger NW. Tuberculosis following solid organ transplantation. Transpl Infect Dis. 2010;12(2):106-12. https://doi org/10.1111/j.1399-3062.2009.00475.x

17. Eyüboğlu FÖ, Küpeli E, Bozbaş SS, Ozen ZE, Akkurt ES, Aydoğan $C$, et al. Evaluation of pulmonary infections in solid organ transplant recipients: 12 years of experience. Transplant Proc. 2013;45(10):345861. https://doi.org/10.1016/j.transproceed.2013.09.024

18. Aslani J, Einollahi B. Prevalence of tuberculosis after rena transplantation in Iran. Transplant Proc. 2001;33(5):2804-5. https:// doi.org/10.1016/S0041-1345(01)02197-2

19. Kaaroud H, Beji S, Boubaker K, Abderrahim E, Ben Hamida F Ben Abdallah TB, et al. Tuberculosis after renal transplantation. Transplant Proc. 2007;39(4):1012-3. https://doi.org/10.1016/j. transproceed.2007.02.032

20. Mortensen E, Hellinger W, Keller C, Cowan LS, Shaw T, Hwang S et al. Three cases of donor-derived pulmonary tuberculosis in lung transplant recipients and review of 12 previously reported cases: opportunities for early diagnosis and prevention. Transpl Infect Dis 2014;16(1):67-75. https://doi.org/10.1111/tid.12171

21. Kesten S, Chaparro C. Mycobacterial infections in lung transplant recipients. Chest. 1999;115(3):741-5. https://doi.org/10.1378/ chest.115.3.741

22. Schulma LL, Htun T, Staniloae C, McGregor CC, Austin JH. Pulmonary nodules and masses after lung and heart-lung transplantation. J Thorac Imaging. 2000;15(3):173-9. https://doi.org/10.1097/00005382200007000-00004

23. Ram R, Swarnalatha G, Prasad N, Dakshinamurty KV. Tuberculosis in renal transplant recipients. Transpl Infect Dis. 2007;9(2):97-101. https://doi.org/10.1111/j.1399-3062.2006.00182.x

24. Shreeniwas R, Schulman LL, Berkmen YA, McGregor CC, Austin JH. Opportunistic bronchopulmonary infections after lung transplantation: clinical and radiographic findings. Radiology. 1996;200(2):349-56. https://doi.org/10.1148/radiology.200.2.8685324

25. Schulma LL, Scully B, McGregor CC Austin JH. Pulmonary tuberculosis after lung transplantation. Chest. 1997;111(5):1459-62. https://doi.org/10.1378/chest.111.5.1459

26. Pereira M, Gazzoni FF, Marchiori E, Irion K, Moreira J, Giacomell $\mathrm{IL}$, et al. High-resolution CT findings of pulmonary Mycobacterium tuberculosis infection in renal transplant recipients. $\mathrm{Br} \mathrm{J}$ Radiol. 2016;89(1058):20150686. https://doi.org/10.1259/bjr.20150686

27. Malouf MA, Glanville AL. The spectrum of mycobacterial infection after lung transplantation. Am J Respir Crit Care Med. 1999;160(5 Pt 1):1611-6. https://doi.org/10.1164/ajrccm.160.5.9808113

28. Jiang $T$, Xue F, Zheng X, Yu H, Tao X, Xiao X, et al. Clinical data and CT findings of pulmonary infection caused by different pathogens afte kidney transplantation. Eur J Radiol. 2012;81(6):1347-52. https://doi. org/10.1016/j.ejrad.2011.03.070

29. Lyu J, Lee SG, Hwang S, Lee SO, Cho OH, Chae EJ, et al. Chest computed tomography is more likely to show latent tuberculosis foc than simple chest radiography in liver transplant candidates. Liver Transpl. 2011;17(8):963-8. https://doi.org/10.1002/lt.22319

30. Meyers BR, Papanicolaou GA, Sheiner P, Emre S, Miller C. Tuberculosis in orthotopic liver transplant patients: increased toxicity of recommended agents; cure of disseminated infection with nonconventional regimens. Transplantation. 2000;69(1):64-9. https:// doi.org/10.1097/00007890-200001150-00013

31. Giacomelli IL, Schuhmacher Neto R, Nin CS, Cassano PS, Pereira M1, Moreira JDS, et al. High-resolution computed tomography findings of pulmonary tuberculosis in lung transplant recipients. Bras Pneumol. 2017;43(4):270-273. https://doi.org/10.1590/s180637562016000000306

32. Schuhmacher Neto R, Giacomelli IL, Schuller Nin C, da Silva Moreira J, Comaru Pasqualotto A, Marchiori E, et al. High-resolution CT findings of pulmonary tuberculosis in liver transplant patients. Clin Radiol. 2017;72(10):899.e9-899.e14. https://doi.org/10.1016/j. crad.2017.05.006

33. Winthrop KL, Kubak BM, Pegues DA, Hufana C, Costamagna $P$ 
Desmond $\mathrm{E}$, et al. Transmission of mycobacterium tuberculosis via lung transplantation. Am J Transplant. 2004;4(9):1529-33. https://doi. org/10.1111/j.1600-6143.2004.00536.x

34. Ardalan MR, Shoja MM, Ghabili K. Concomitant pulmonary tuberculosis and tuberculous appendicitis in a recipient of a renal transplant: a case report. J Med Case Rep. 2011;5:191. https://doi. org/10.1186/1752-1947-5-191

35. Boedefeld RL, Eby J, Boedefeld WM 2nd, Stanley D, Lau LC, Kern $\mathrm{JA}$, et al. Fatal Mycobacterium tuberculosis infection in a lung transplant recipient. J Heart Lung Transplant. 2008;27(10):1176-8. https://doi.org/10.1016/..healun.2008.07.009

36. Shitrit D, Bendayan D, Saute M, Kramer MR. Multidrug resistant tuberculosis following lung transplantation: treatment with pulmonary resection. Thorax. 2004;59(1):79-80.

37. Miller RA, Lanza LA, Kline JN, Geist LJ. Mycobacterium tuberculosis in lung transplant recipients. Am J Respir Crit Care Med. 1995;152(1):374-6. https://doi.org/10.1164/ajrccm.152.1.7599848

38. Place S, Knoop C, Remmelinsk M, Baldassarre S, Van Vooren JP, Jacobs $F$, et al. Paradoxical worsening of tuberculosis in a heart-lung transplant recipient. Transpl Infect Dis. 2007;9(3):219-24. https://doi. org/10.1111/j.1399-3062.2006.00194.x

39. Lee J. Yew WW, Wong CF, Wong PC, Chiu CS. Multidrug-resistant tuberculosis in a lung transplant recipient. J Heart Lung Transplant. 2003;22(10):1168-73. https://doi.org/10.1016/S1053-2498(02)01189-0

40. Kumar D, Budev M, Koval C, Hellinger WC, Gordon SM, Tomford JW. Donor-derived tuberculosis (TB) infection in lung transplant despite following recommended algorithm. Am J Transplant.
2013;13(8):2225-6. https://doi.org/10.1111/ajt.12344

41. Kukrej N, Cook GJ, Pattison JM. Positron-emission tomography used to diagnose tuberculosis in a renal transplant patient. Am J Transplant. 2002;2(1):105-7. https://doi.org/10.1034/j.1600-6143.2002.020117.x

42. Carlsen SE, Bergin CJ. Reactivation of tuberculosis in a donor lung after transplantation. AJR Am J Roentgenol. 1990;154(3):495-7. https://doi.org/10.2214/ajr.154.3.2106211

43. Wong KK, Lim ST, Yeung CK, Ng WL, Ong GB. Disseminated tuberculosis in a renal transplant recipient. Aust N Z J Surg. 1983;53(2):173-5. https://doi.org/10.1111/j.1445-2197.1983.tb02422.x

44. Duggal R, Rajwanshi A, Gupta N, Lal A, Singhal M. Polymicrobial lung infection in postrenal transplant recipient diagnosed by fine-needle aspiration cytology. Diagn Cytopathol. 2010;38(4):294-6.

45. Tan BH, Cheah FK, Chew S, Ahmed O. A renal transplant recipient with pulmonary nodules. Transpl Infect Dis. 2005;7(1):18-25. https:// doi.org/10.1111/j.1399-3062.2005.00080.x

46. Saurborn DP, Fishman JE, Boiselle PM. The imaging spectrum of pulmonary tuberculosis in AIDS. J Thorac Imaging. 2002;17(1):28-33. https://doi.org/10.1097/00005382-200201000-00003

47. Castañer E, Gallardo X, Mata JM, Esteba L. Radiologic approach to the diagnosis of infectious pulmonary diseases in patients infected with the human immunodeficiency virus. Eur J Radiol. 2004;51(2):114-29. https://doi.org/10.1016/j.ejrad.2004.03.008

48. Almeida LA, Barba MF, Moreira FA, Bombarda S, Felice AS, Calore EE. Computed tomography findings of pulmonary tuberculosis in adult AIDS patients. Radiol Bras. 2011:44(1):13-9. https://doi. org/10.1590/S0100-39842011000100007 